\title{
ANÁLISIS DE FACTIBILIDAD \\ PARA EL INCREMENTO DE CAPACIDAD \\ INSTALADA EN EL ALMACÉN DEL CENTRO \\ DE DISTRIBUCIÓN DE UNA EMPRESA EN CANCÚN
}

Felipe Pérez, Paola Alfaro,
Luz María De La Garza
y Francisco Lerma*

Universidad del Caribe, Quintana Roo, México

Recibido: 14 de febrero del 2020 / Aprobado: 22 de abril del 2020

doi: 10.26439/ing.ind2020.n038.4813

RESUMEN: La investigación se desarrolló en el almacén del centro de distribución Sigma Alimentos Cancún, empresa dedicada al almacenamiento y distribución de alimentos congelados. El problema se centró en determinar la capacidad real de almacenamiento de la empresa y encontrar una propuesta para el incremento en el almacenamiento en frío que satisfaga la demanda de los próximos años. Se utilizó una metodología de planeación y evaluación de proyectos de 4 fases de estudio: de mercado, técnico, económico-financiero y de resultados. En el desarrollo del proyecto están los análisis de los 3 estudios y sus respectivos resultados. Al final de esta investigación se propone la expansión del espacio de almacenamiento, aumentando su capacidad instalada en 67500 kilogramos, lo que permitirá su correcto funcionamiento en al menos 5 años, demostrando que, incluso, podría ser operado por 9 años más.

Palabras clave: estudios de viabilidad / capacidad de almacenamiento / centros de distribución / alimentos congelados

*jperez@ucaribe.edu.mx, paoalfaro.2@gmail.com, luzmadlgarza@gmail.com, davidlermaa32@gmail.com 


\title{
FEASIBILITY ANALYSIS FOR INCREASING THE INSTALLED CAPACITY OF A COMPANY'S DISTRIBUTION CENTER/WAREHOUSE IN CANCUN
}

\begin{abstract}
The project was conducted at the distribution center/warehouse of Sigma Alimentos Cancún, a frozen-food warehouse and distribution company. The company aimed at determining its actual storage capacity and presenting a proposal to increase its cold storage capacity to meet the demands of the coming years. A four-phase project planning and evaluation methodology was used: market study, technical study, financial and economic study, and results. During the project, these three studies and their results were analyzed. The results of this research suggest to expand the warehouse by increasing its installed capacity to 67,500 kilograms. This expansion will allow the correct operation of the distribution center/warehouse during a minimum of 5 years and even for 9 years.
\end{abstract}

Keywords: feasibility studies / storage capacity / distribution centers / frozen foods 


\section{INTRODUCCIÓN}

En los últimos 10 años la tasa de crecimiento poblacional en el estado de Quintana Roo (México) ha aumentado un 2,49 \%, de acuerdo con datos obtenidos por el Instituto Nacional de Estadística y Geografía (INEGI, s.f.). Este crecimiento poblacional sumado a los cambios en las tendencias de los consumidores ha originado que la empresa Sigma Alimentos Cancún incremente la adquisición de productos para satisfacer la demanda e introducirse a nuevos mercados. Debido a esto, el almacén de la empresa, ubicado en la ciudad de Cancún, ha sobrepasado su capacidad de almacenaje de 80 toneladas $y$, actualmente, tienen entre 100 y 120 toneladas diarias para poder abastecer la mayor parte de la demanda. El gerente del almacén ha solicitado una ampliación, sin embargo, hasta el momento no se cuenta con ningún estudio o evidencia documental que pruebe que el almacén sobrepase su capacidad máxima y sea necesaria una ampliación. La figura 1 muestra el layout con la distribución actual del almacén.

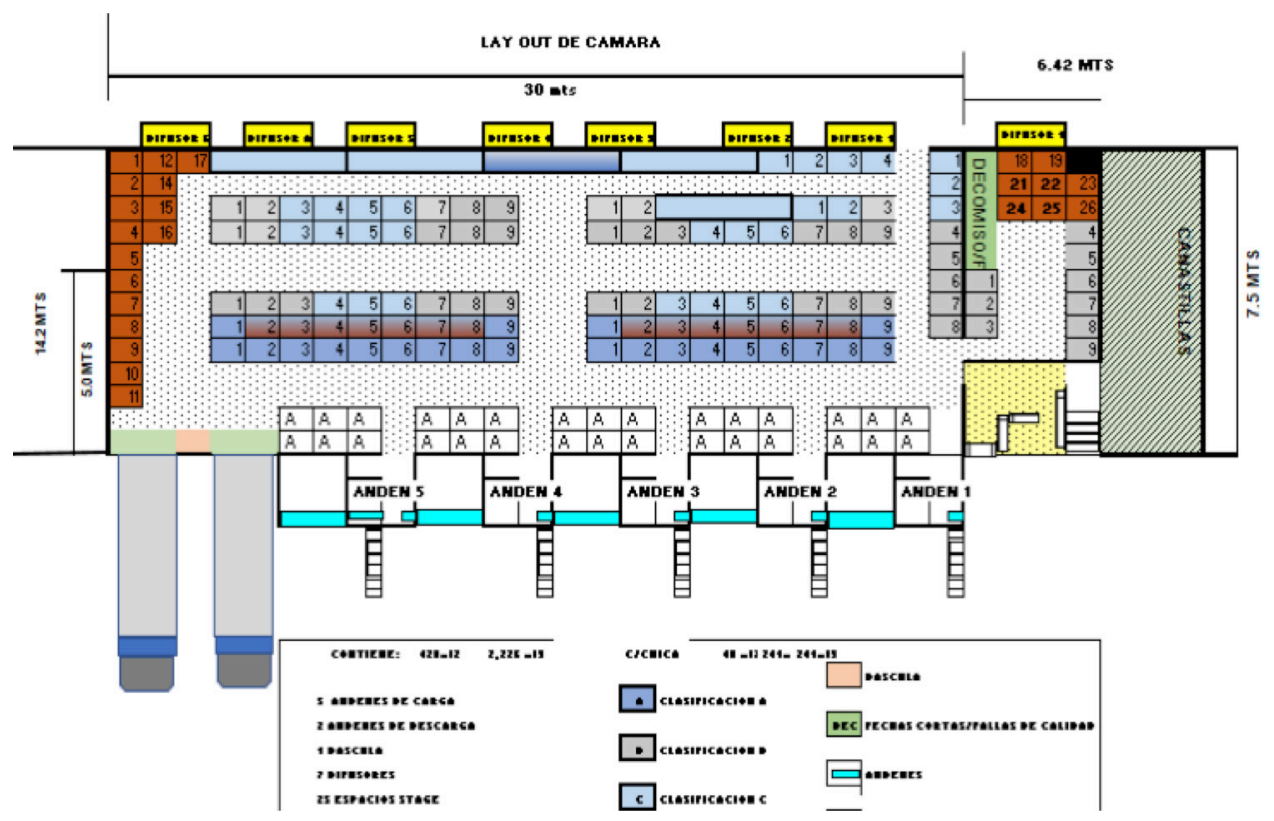

Figura 1. Layout del almacén del centro de distribución (CEDIS) de Cancún Fuente: Sigma Alimentos Cancún (2017) 
La figura 2 muestra dos panorámicas de la distribución del almacén que inicialmente se estableció al comienzo de las operaciones del centro de distribución (CEDIS). La clasificación desde su inicio fue $A B C$. Sin embargo, dicha distribución actualmente puede variar de acuerdo con el espacio y el acomodo de los productos dentro del almacén.
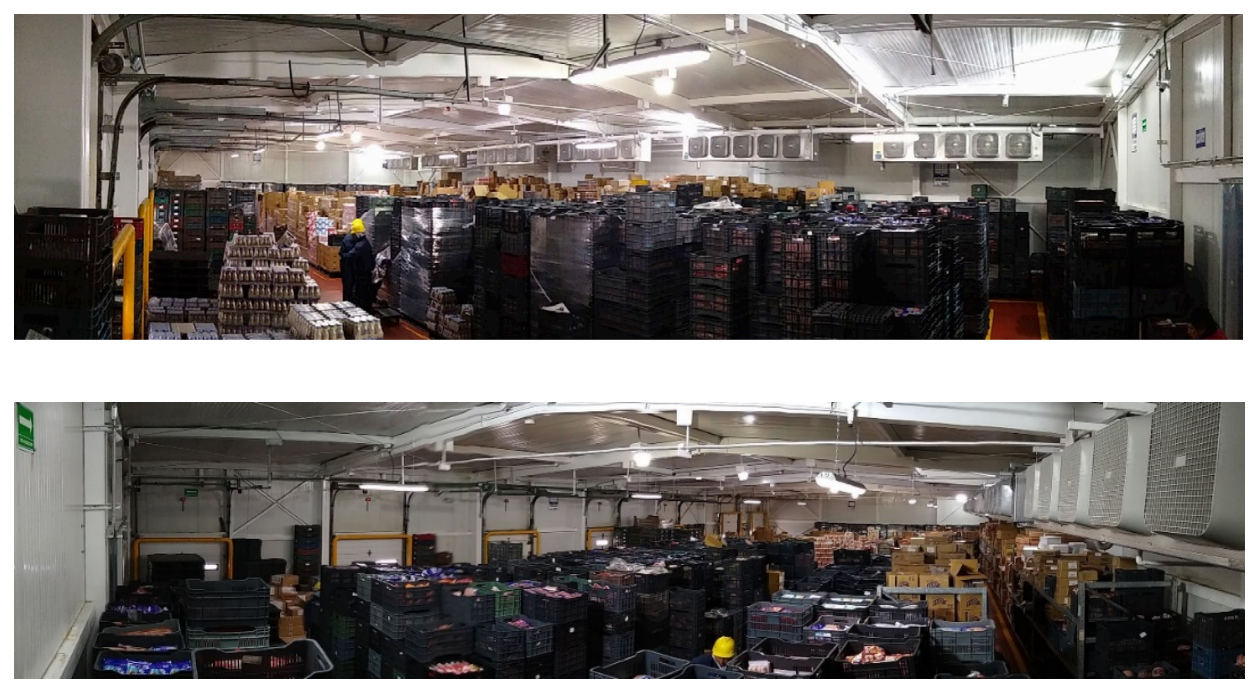

Figura 2. Fotografía panorámica en dos ángulos diferentes del almacén Sigma Alimentos Cancún Fuente: Sigma Alimentos Cancún (2019)

Sigma Alimentos es una compañía dedicada a la elaboración, comercialización y distribución de alimentos refrigerados. En la actualidad se encuentra en una etapa de crecimiento, expandiendo sus mercados, innovando con nuevos productos y creando alianzas estratégicas por todo el mundo. En el año 2017, Sigma Alimentos adquirió la Sociedad Suizo Peruana de Embutidos, S.A. (Supemsa), compañía que se dedica a la producción y comercialización de carnes frías y lácteos en el Perú. En el mismo año, Sigma Alimentos adquirió el 51 \% de las acciones de Caroli Foods Group, B.V. (Caroli), compañía que se dedica a la producción y comercialización de carnes frías y comidas preparadas en Rumania (Vivanco, 2017). Se piensa que estas acciones demandan mayor eficiencia en sus procesos de almacenaje y distribución.

Sigma Alimentos inicia operaciones en la ciudad de Cancún una década anterior, en 1999, y en ese mismo año construye el centro de distribución (CEDIS) para el almacenamiento y distribución de sus productos, esto debido al crecimiento que estaba teniendo la zona sureste del país y por el incremento en la demanda de los productos. La sucursal de Sigma Alimentos Cancún se ubica en la carretera Costera del Golfo, 1009. En el almacén se resguardan diariamente más de 100 toneladas de 547 tipos de productos que son 
distribuidos hacia las zonas de Cancún, Isla Mujeres, Cozumel, Puerto Morelos, Playa del Carmen, Holbox y Tulum.

El CEDIS de Sigma Alimentos Cancún cuenta con 271 empleados distribuidos en el área administrativa y operativa, en áreas de oficina y en un almacén frío, el cual cuenta con un equipo de refrigeración con un monitor de temperatura y 4 compresores que mantienen una temperatura de 0,23 a $5^{\circ} \mathrm{C}$.

Las ventas están dirigidas a 3 tipos de clientes: autoservicio, conveniencia y ventas al detalle. Los clientes de autoservicio son grandes cadenas de supermercados como Soriana, Chedraui, Sams, Costco, Walmart y San Francisco de Asís. Los clientes de tiendas de conveniencia son mayoristas, pero con una demanda menor que los de autoservicio, empresas como Dunosusa, Oxxo, Extra, Circle K. Por último, los clientes de venta al detalle son pequeñas tiendas locales como abarrotes y fruterías que, a diferencia de los otros dos tipos de cliente, no realizan pedidos, sino que los conductores actúan como vendedores directos a este tipo de clientes, llevando productos en las camionetas y surten lo que se les solicita en el momento o con lo que cuenta el conductor en el vehículo.

Debido a que era necesario determinar la capacidad real del almacén para diseñar una propuesta de ampliación y satisfacer la demanda de los próximos años, se revisaron trabajos relacionados a la gestión, optimización de espacios y estudios de factibilidad para ampliaciones de almacenes.

Contreras y Quintero (2012) realizaron una propuesta de mejora para la gestión de varios almacenes de materia prima de una empresa del sector químico y del calzado. Utilizaron una metodología bajo el esquema de un proyecto factible con ayuda de fuentes documentales, observación, entrevistas y herramientas analíticas como diagramas de flujo, diagrama de Ishikawa, cálculo del costo-beneficio de la aplicación y el método de clasificación $\mathrm{ABC}$.

Dematteis y Croci (2014) elaboraron un estudio de optimización de un almacén de insumos para la elaboración de cerveza, con escaso espacio para el acomodo de los insumos, incurriendo en otros problemas como mayor tiempo de movimiento dentro del almacén, mayor tiempo de carga y descarga que representan costos adicionales al proceso de almacenaje. Para ello escogieron la metodología de rediseño y mejora de procesos, esto es una combinación entre información documental y de campo, utilizando herramientas de recolección de datos, como entrevistas, cuestionarios al personal del almacén, diagramas causa-efecto, gráficas y análisis de costos de operación. Se tomaron en cuenta las inversiones necesarias para cada opción, así como también sus períodos de repago. También calcularon indicadores, tales como el valor actual neto (VAN) y la tasa interna de retorno (TIR). 
Albán (2016) realizó un estudio de factibilidad para la ampliación y diversificación de un almacén que resguarda productos de pañalera y diversos artículos para niños, el cual surgió como parte de la necesidad de la empresa de querer tener un mejor sistema de almacenamiento para sus productos y poder administrar mejor la diversificación de los mismos, con el fin de incrementar los niveles de rentabilidad del almacén. Se basó en una adaptación de la metodología de Baca Urbina (2013), que abarca los cuatro tipos de estudio, y con ello obtuvo la información necesaria para una correcta toma de decisiones final para comprobar la factibilidad de ampliar el almacén.

Estos son ejemplos en donde se ha avanzado en ese campo, experiencias nacionales e internacionales, en los últimos años.

\section{METODOLOGÍA}

Para este análisis de factibilidad, se utilizó una metodología con tres tipos de estudios para obtener los resultados deseados, tomando como base los estudios planteados en la metodología de Baca Urbina (2013) para la formulación y evaluación de proyectos. Esta metodología tiene un enfoque cuantitativo.

Para fines del proyecto, el estudio económico y financiero se realizó en conjunto, y el estudio socio-económico no se ejecutó debido a que el impacto del proyecto no era del todo conocido con certeza, además, la decisión final era de la empresa. Las fases de la metodología antes mencionada son:

Fase 1. Estudio de mercado: es la determinación y cuantificación de la demanda y la oferta, el análisis de los precios y el estudio de la comercialización.

Fase 2. Estudio técnico: el estudio técnico puede subdividirse en cuatro partes: determinación del tamaño óptimo de la planta, determinación de la localización óptima de la planta, ingeniería del proyecto y análisis organizativo.

De acuerdo con la información obtenida sobre la infraestructura del almacén, equipos, herramientas y productos, se analizó la capacidad instalada y distribución del almacén y los equipos utilizados en la operación para poder realizar el análisis de la situación y evaluar una posible propuesta.

Fase 3. Estudio económico-financiero: comienza con la determinación de los costos totales y de la inversión inicial, a partir de los estudios de ingeniería. Continúa con la determinación de la depreciación y amortización de toda la inversión inicial. Los aspectos que sirven de base son la determinación de la tasa de rendimiento mínima aceptable y el cálculo de los flujos netos de efectivo. Ambos, tasa y flujos, se calculan con y sin financiamiento. Los flujos provienen del estado de resultados proyectados para el horizonte de tiempo seleccionado. Cuando se habla de "financiamiento" es necesario mostrar cómo 
funciona y cómo se aplica en el estado de resultados, pues modifica los flujos netos de efectivo. De esta forma se seleccionó un plan de financiamiento, mostrando su cálculo tanto en la forma de pagar intereses como en el pago del capital.

Con base a la información recaudada, previamente y después de la realización del análisis técnico, se determinó la inversión inicial incremental, cálculo de depreciación y amortización de la propuesta, tomando en cuenta nuevas adquisiciones en equipo, costos y un estado de resultados incremental. De igual manera, se realizó la determinación de la rentabilidad económica.

Fase 4. Resumen y conclusiones: con los resultados obtenidos en los 3 análisis, se obtuvo un resultado final sobre la factibilidad de ampliación del almacén frío de la empresa, mostrando que sí es factibles, en todos los aspectos, la ampliación del almacén.

\section{RESULTADOS}

\subsection{Fase 1: estudio de mercado}

La empresa Sigma Alimentos ya tenía identificado su mercado por lo cual la investigación se limita a los estudios técnico y al económico-financiero.

\subsection{Fase 2: estudio técnico}

Para la proyección de la demanda se tomaron los datos históricos proporcionados por la empresa sobre las ventas en kilogramos de los últimos tres años y las ventas obtenidas de los primeros 5 meses del año 2019. Los cuales se capturaron en el software Minitab 18, para obtener la ecuación de regresión lineal y la gráfica de la línea ajustada de los valores, mostradas en la figura 3.

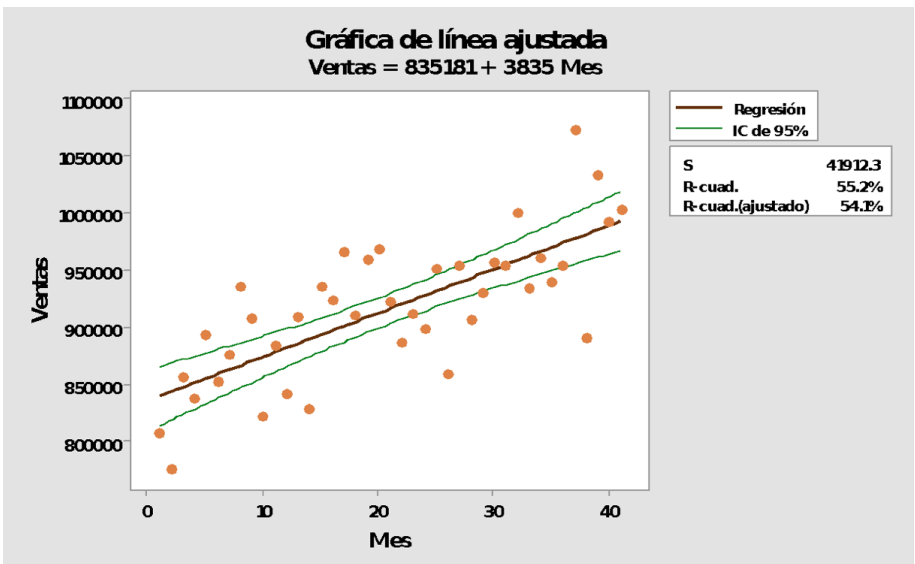

Figura 3. Ecuación de regresión lineal y gráfica de línea de valores ajustados Elaboración propia 
El resultado de la $R$ cuadrada ya con los datos ajustados, arrojó un 54,05 \%. El ajuste de regresión lineal a nuestro modelo de ventas no es totalmente confiable, sin embargo, con el resultado del análisis de varianza (figura 4) con una $F$ de 48,05, un valor $P$ menor al nivel de significancia estándar de alpha $=0,05$ y la comprobación de los supuestos de los residuales de la muestra (figura 5) dieron un resultado favorable, y se tomó como fidedigna la ecuación de regresión lineal para la estimación de la demanda futura. Sin embargo, se realizó otro modelo estadístico para comparar ambos modelos.

Análisis de varianza

\begin{tabular}{lrcccc}
\multicolumn{1}{c}{ Fuente } & GL & SC & MC & $F$ & $P$ \\
\hline Regresión & 1 & $8,44126 \mathrm{E}+10$ & $8,44126 \mathrm{E}+10$ & 48,05 & 0,000 \\
Error & 39 & $6,85088 \mathrm{E}+10$ & $1,75664 \mathrm{E}+09$ & & \\
& 40 & $1,52921 \mathrm{E}+11$ & & & \\
\hline
\end{tabular}

Figura 4. Resumen del modelo de regresión lineal simple de ventas y meses Elaboración propia

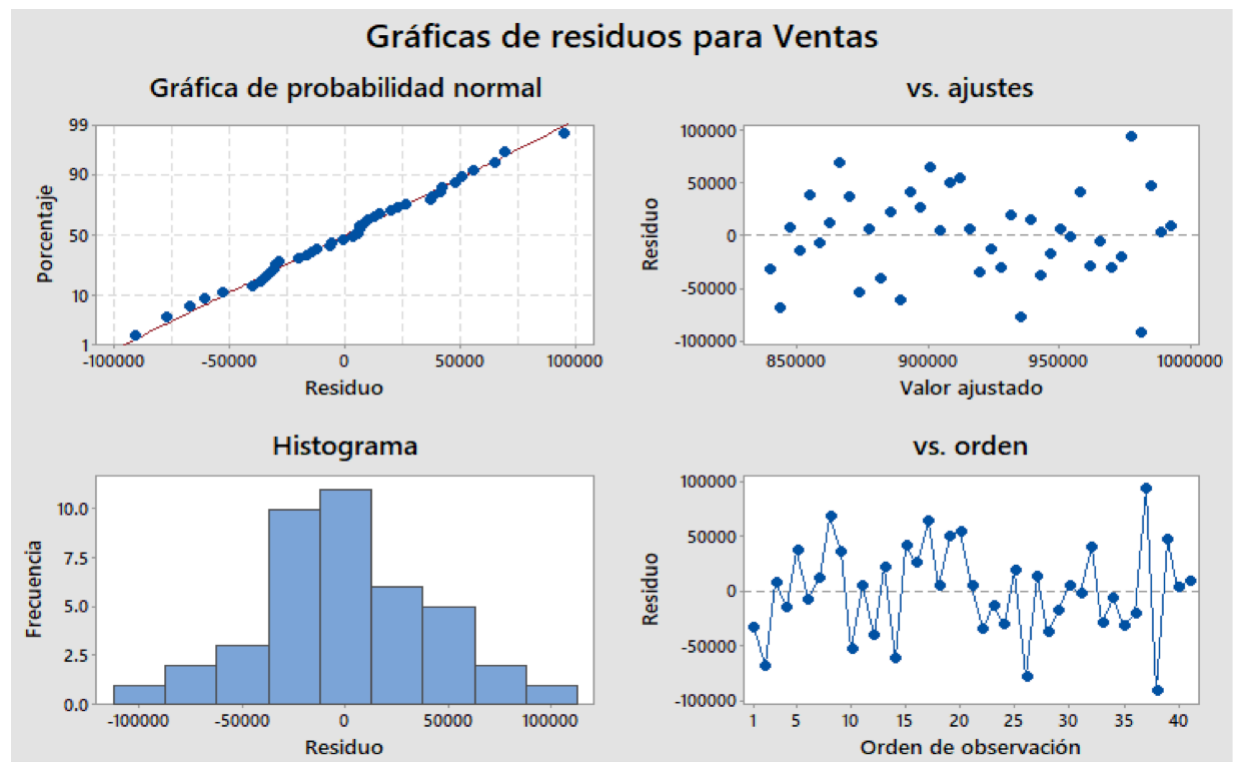

Figura 5. Comprobación de supuestos de normalidad

Elaboración propia 


\subsubsection{Demostración de resultados con modelo series de tiempo}

Para tener una comparativa del modelo de regresión lineal mostrado anteriormente, se realizó un modelo de series de tiempo para comprobar y comparar el pronóstico del mes número 60, utilizando la ecuación de regresión comparándola con el resultado obtenido del modelo de series de tiempo.

El resultado del valor en kilogramos vendidos en el mes número 60 , con el método de regresión lineal fue 1249361.

Se considera el mismo período de tiempo y se ingresan los valores al programa Minitab 18:

- Se realizó la gráfica de series de tiempo y se observó el comportamiento de los datos, detallando que la pendiente tenía tendencia positiva.

- Se comprobó, con el método por descomposición de series de tiempo, a través de regresión lineal e índices estacionales, que la longitud estacional son los 12 pronósticos (meses del año).

El estudio nos arrojó los siguientes resultados:

- MAPE-Error porcentual absoluto medio (es decir, que por cada vez que pronosticamos nos equivocamos, con respecto a datos reales), que es el $2 \%$ de la desviación.

- MAD-Desviación media absoluta-promedio, cuánto me desvío en funciones de unidades absolutas.

- MSD-Desviación cuadrática media, tipo de varianza que existe entre nuestro conjunto de datos.

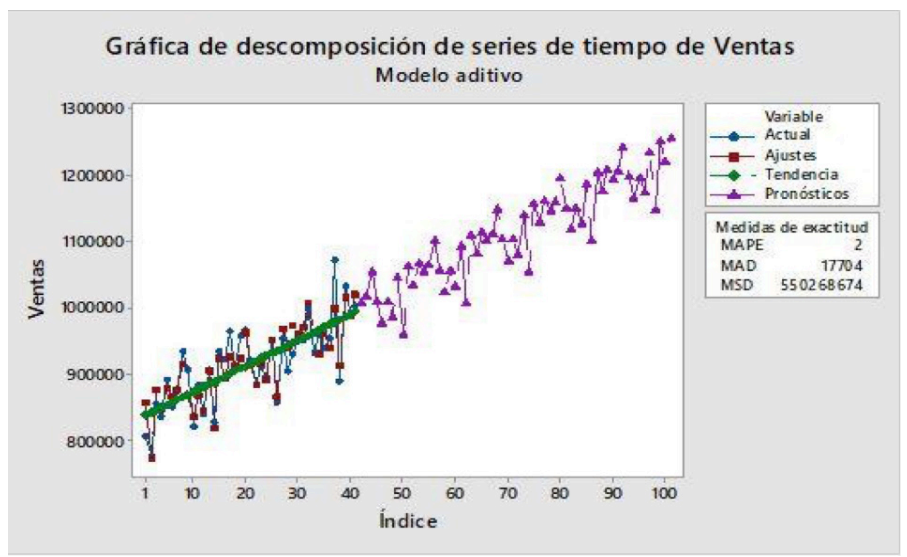

Figura 6. Modelo aditivo de series de tiempo

Elaboración propia 


\subsubsection{Estimación de la demanda}

Después de corroborar con el método de series de tiempo la similitud del resultado del mes 60 , se prosiguió con el primer método para la estimación de la demanda futura, acorde a la metodología establecida.

Con la obtención de la ecuación de regresión lineal, la cual es $835181+3835$ x mes, se pronosticó la demanda de los productos para los próximos 5 años, la cual se muestra en la figura 7.

La demanda que se necesitará abastecer en el mes 60, es decir, en el mes de diciembre del año 2024, será de 1249361 kilogramos.

VENTAS ESTIMADAS EN KILOS PARA LOS PROXIMOS 5 AÑOS

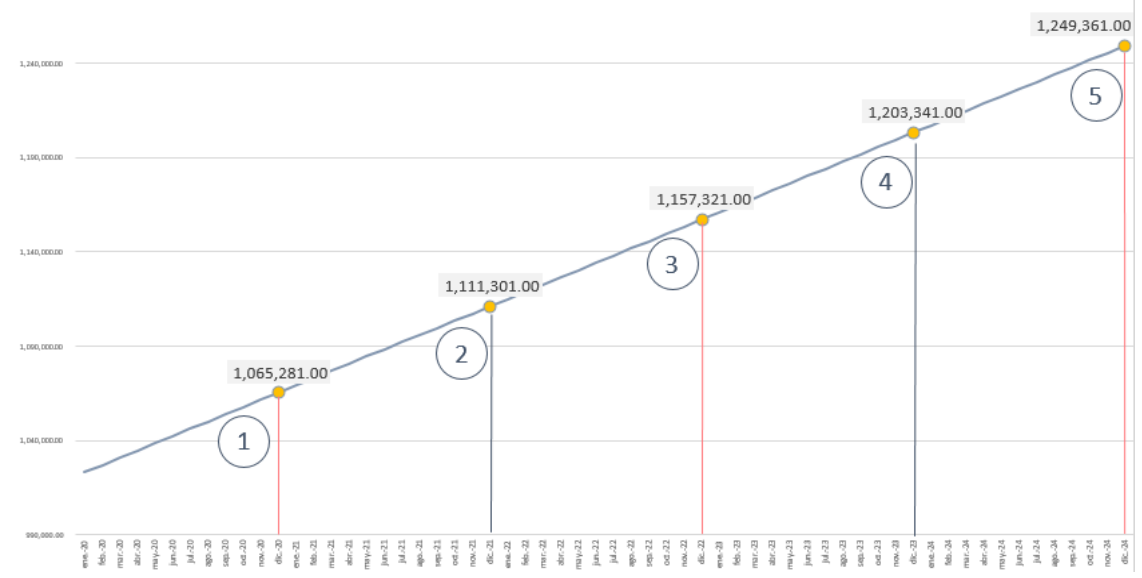

Figura 7. Estimación de demanda de Sigma Alimentos Cancún

Elaboración propia

\subsubsection{Estimación de la capacidad instalada actual}

Una vez encontrada la proyección de la demanda de los próximos 5 años, se debe establecer la capacidad instalada con la cual tendrá que contar el almacén del CEDIS para poder abastecer, de forma óptima, aquella demanda. Para ello, primero es importante conocer la capacidad actual, ya que las 80 toneladas que se establecieron en 1999 fueron planteadas para esa época y se han realizado modificaciones a la distribución a causa del incremento de la demanda en los pasados 20 años.

Para determinar la capacidad actual, se tomó como base el layout y se dividieron las secciones en las cuales se almacena el producto, sin tomar en cuenta los andenes, enumerándolas del 1 al 8. Posteriormente, se contó el número de tarimas por sección, 
de acuerdo a las dimensiones de las tarimas, obteniendo así las áreas totales de cada sección.

Una vez con las secciones y el número de tarimas definidas, se estimó el peso promedio por tarima con registros obtenidos. De esta forma se pudo estimar la capacidad actual real en kilogramos, al igual que el área y el volumen totales destinados para almacenamiento.

Tabla 1

Capacidad instalada por sección

\begin{tabular}{cccccc}
\hline $\begin{array}{c}\text { Área } \\
\text { delimitada }\end{array}$ & $\begin{array}{c}\text { Número } \\
\text { de tarimas }\end{array}$ & $\begin{array}{c}\text { Peso } \\
\text { promedio }\end{array}$ & $\begin{array}{c}\text { Peso en kilogramos } \\
\text { por área }\end{array}$ & $\begin{array}{c}\text { Metros } \\
\text { cuadrados }\end{array}$ & $\begin{array}{c}\text { Metros } \\
\text { cúbicos }\end{array}$ \\
\hline 1 & 17 & 750 & 12750 & 20,4 & 40,8 \\
2 & 18 & 750 & 13500 & 21,6 & 43,2 \\
3 & 27 & 750 & 20250 & 32,4 & 64,8 \\
4 & 18 & 750 & 13500 & 21,6 & 43,2 \\
5 & 27 & 750 & 20250 & 32,4 & 64,8 \\
6 & 20 & 750 & 15000 & 24 & 48 \\
7 & 8 & 750 & 6000 & 9,6 & 19,2 \\
Total & 17 & 750 & 12750 & 20,4 & 40,8 \\
\hline
\end{tabular}

Elaboración propia

De acuerdo con la tabla 1, la capacidad actual del almacén es de 114000 kilogramos en óptimas condiciones; se refiere a cuando se hace uso, únicamente, de las áreas definidas para almacenamiento, ya que en ocasiones fue usual que los pasillos se viesen comprometidos, cuando la capacidad en el año 2019 no era suficiente.

\subsubsection{Estimación de capacidad instalada a 5 años}

Después de la obtención de la demanda futura y la capacidad real actual, se estimó la capacidad adicional necesaria para abastecer la totalidad de la demanda que tendría el almacén en los próximos 5 años.

Para ello, fue necesario conocer el tiempo promedio de vida de los productos dentro del almacén, el cual se tiene en cuenta desde el momento en que el producto ingresa por medio de los andenes, al momento en el que sale por los mismos. El proceso incluye el tiempo de recepción, tiempo de almacenaje y tiempo de armado de pedidos. Dicha 
información forma parte del KPI (por sus siglas en inglés, key performance indicator), establecido por la empresa para monitorear la eficiencia en el proceso de almacenaje. De acuerdo con estos KPI, el tiempo promedio de vida de los productos dentro del almacén es de 3,5 días.

Para poder estimar la capacidad instalada por mes, medida de tiempo utilizada para el pronóstico de ventas, se dividió el número promedio de días de los meses, entre el tiempo promedio de vida de los productos en el almacén, y el resultado obtenido fue 8,57 , es decir, que generalmente durante un mes se cumplen 8,57 períodos de vida de los productos entrantes.

Posteriormente, se multiplicó el número de períodos de vida de los productos por la capacidad real actual, para estimar los kilogramos disponibles en un mes.

El resultado fue: 977 142,85 kilogramos.

A este resultado se le restó la venta de cada mes pronosticado y se dividió entre el número de períodos de vida de los productos, los resultados se muestran en la figura 8 .

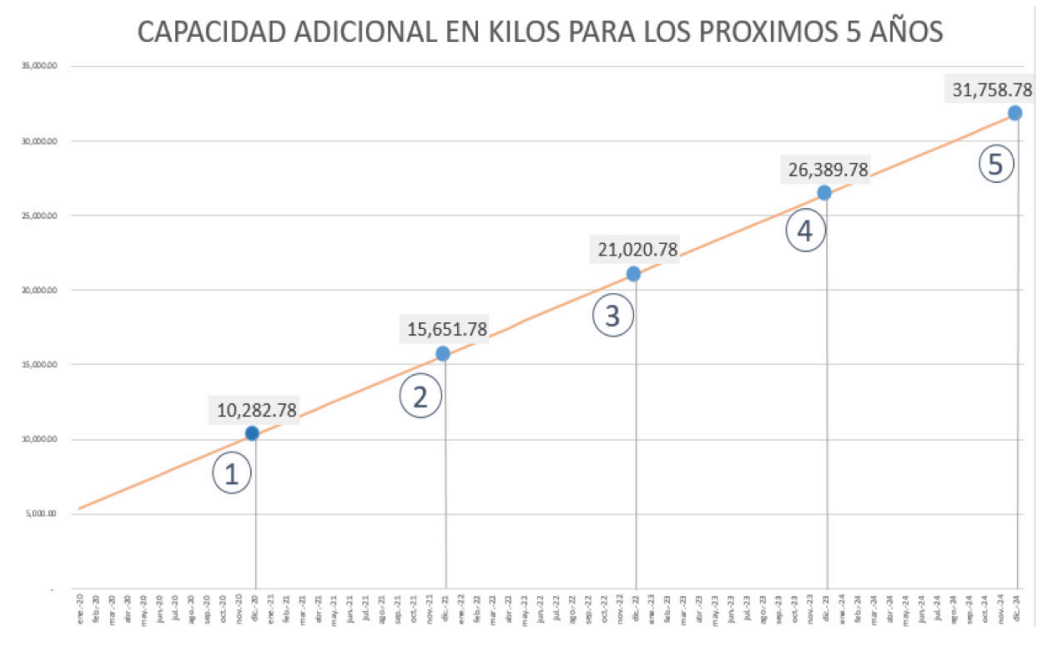

Figura 8. Estimación de capacidad de Sigma Alimentos Cancún

Elaboración propia

Es decir, en el mes número 60 pronosticado, se necesitarán 31 758,78 kilogramos de capacidad adicional para abastecer la totalidad de la demanda en dicho período. 


\subsubsection{Determinación del tamaño óptimo del almacén}

Los resultados obtenidos, previamente, determinaron la capacidad instalada futura con la que debía cumplir el almacén para satisfacer su demanda en los próximos 5 años. Por ello, se consideró la siguiente propuesta para cumplir con el incremento de 31758 kilogramos de producto.

\subsubsection{Propuesta: ampliación del almacén}

La propuesta evaluada para el proyecto fue determinada en conjunto con el jefe de almacén al mostrar los avances del proyecto, se llegó a la decisión de considerar una ampliación menor que pudiera aprovecharse al máximo, sin necesidad de afectar la operación del almacén.

Al costado derecho del almacén se encuentra un espacio el cual es utilizado, en ocasiones, para resguardar tarimas que no se encuentran en uso. Agregando a este espacio las oficinas administrativas del almacén y el área de resguardo, se logra obtener un área de 9,42 × 14,2 metros, la idea esencial consiste en aprovechar la ampliación para modificar el espacio y obtener mayor altura en el almacenamiento para el uso de 2 racks fijos en forma de ele, uno de 12 metros de altura por 5 de largo y otro de 12 metros de altura por 14 de largo.

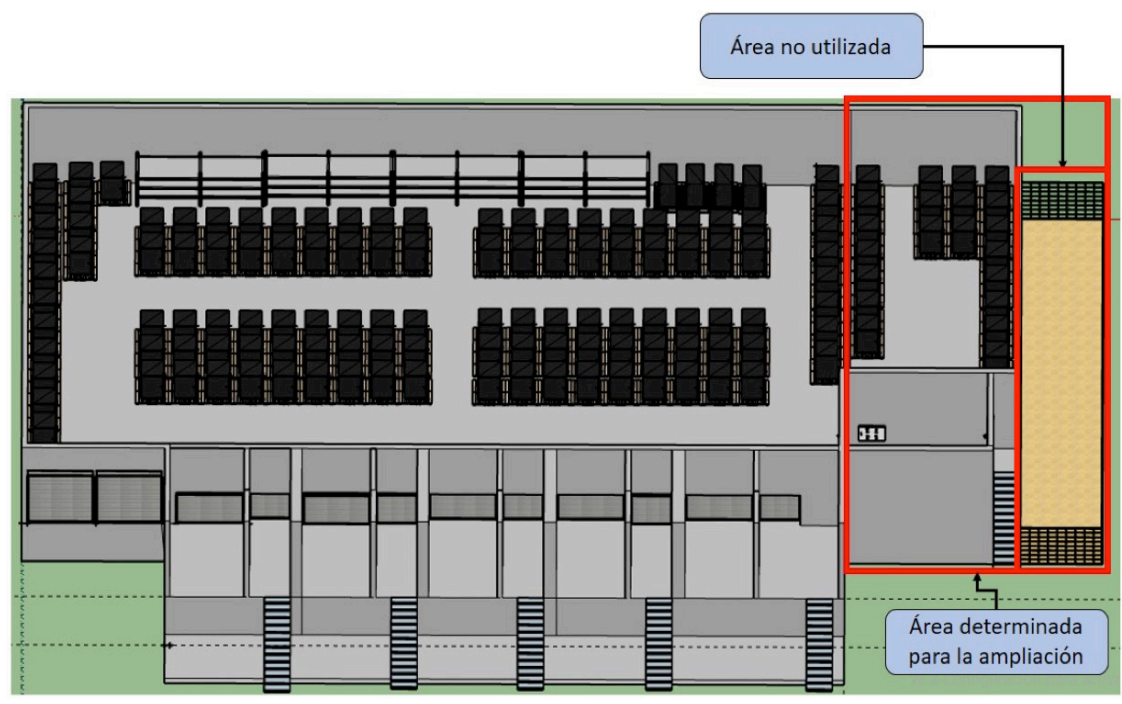

Figura 9. Almacén actual Sigma Alimentos Cancún

Elaboración propia 


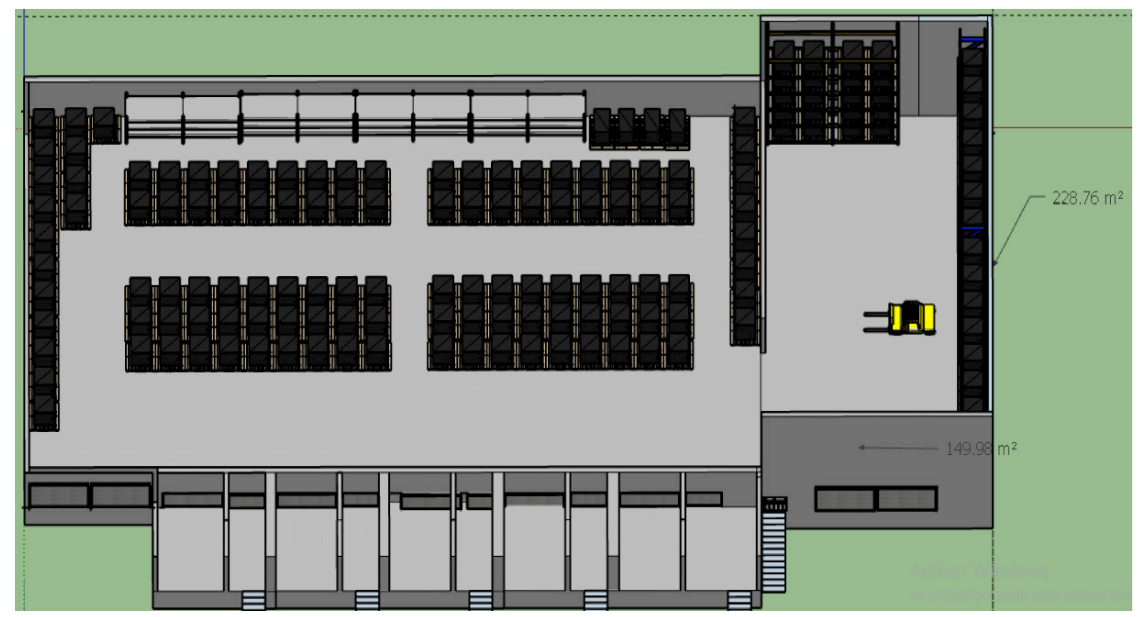

Figura 10. Propuesta 2, ampliación de almacén

Elaboración propia

\subsubsection{Solución para la propuesta}

Ya que el almacén es frío, el material de construcción que se utiliza no es el convencional, la ampliación debe ser realizada con paneles de aislamiento térmico para asegurar que la temperatura sea la adecuada para los productos. Para esto, Mecalux Soluciones de Almacenaje provee los servicios requeridos para la construcción del almacén en las condiciones señaladas. Asimismo, cuentan con racks fijos de múltiples niveles con las especificaciones requeridas para laborar en climas fríos.

Esta propuesta es conveniente porque no se modificaría el método actual de almacenamiento, solo se agregaría un espacio extra al actual, de forma que tampoco se afectaría la operación durante su construcción. Asimismo, incrementaría 90 tarimas al almacén tradicional, lo que representa un incremento de 67500 kilogramos, satisfaciendo igualmente la demanda estimada a 5 años y agregando 35741 kilogramos más, lo que representa un $212 \%$. 
Ingeniería del proyecto

Tabla 2

Equipos y herramientas actuales

\begin{tabular}{|c|c|c|}
\hline Concepto & Cantidad & Descripción \\
\hline Camionetas transportadoras & 47 unidades & $\begin{array}{l}\text { Cuentan con una capacidad de toneladas y } \\
\text { se utilizan para distribuir el producto a los } \\
\text { diferentes clientes. }\end{array}$ \\
\hline Equipo de refrigeración & 8 difusores & $\begin{array}{l}\text { Monitor de control de temperatura y } \\
4 \text { compresores que mantienen una } \\
\text { temperatura de } 0,23 \text { a } 5{ }^{\circ} \mathrm{C} \text {. }\end{array}$ \\
\hline Tarimas & 152 (en promedio) & $\begin{array}{l}\text { Las tarimas son utilizadas para almacenar } \\
\text { las canastillas de productos. }\end{array}$ \\
\hline Canastillas & 41 (en promedio) & $\begin{array}{l}\text { Cada tarima cuenta con aproximadamente } \\
41 \text { canastillas para almacenar productos. }\end{array}$ \\
\hline Patines hidráulicos & 5 & $\begin{array}{l}\text { Los patines se utilizan para transportar las } \\
\text { tarimas. }\end{array}$ \\
\hline Carros transportadores & 5 & $\begin{array}{l}\text { Se utilizan para transportar hasta } \\
5 \text { canastillas. }\end{array}$ \\
\hline $\begin{array}{l}\text { Equipo de seguridad } \\
\text { personal }\end{array}$ & 15 kits & $\begin{array}{l}\text { Casco, chamarra para frío, botas } \\
\text { antiderrapantes, pantalón para frío } \\
\text { y guantes de carga. }\end{array}$ \\
\hline
\end{tabular}

Elaboración propia

Tabla 3

Equipos y herramientas adicionales para la propuesta

\begin{tabular}{|c|c|c|}
\hline Concepto & Cantidad & Descripción \\
\hline Rack fijo & 2 racks & Racks fijos para almacenes fríos de 5 niveles. \\
\hline Montacargas & 1 & Montacargas para pasillos angostos, elevación de hasta \\
\hline Raymond & & $\begin{array}{l}12 \text { metros de altura y con capacidad máxima de } 1500 \\
\text { kilogramos. }\end{array}$ \\
\hline $\begin{array}{l}\text { Paneles de aisla- } \\
\text { miento térmico }\end{array}$ & $\begin{array}{l}656 \text { metros } \\
\text { cuadrados }\end{array}$ & $\begin{array}{l}\text { Paneles con chapas de acero galvanizado, se perfilan con un } \\
\text { acabado grecado, que las hace más resistentes y rígidas. }\end{array}$ \\
\hline $\begin{array}{l}\text { Compresor tipo } \\
\text { tornillo }\end{array}$ & 1 unidad & $\begin{array}{l}\text { Compresor de tipo tornillo marca FERMON modelo EAS-50 de } \\
50 \mathrm{HP} \text { utilizado para el sistema de refrigeración. }\end{array}$ \\
\hline Condensador & 1 unidad & $\begin{array}{l}\text { Condensador marca FRICK ECH 806-103 para el sistema de } \\
\text { refrigeración. }\end{array}$ \\
\hline
\end{tabular}


(continuación)

\begin{tabular}{lll}
\hline $\begin{array}{l}\text { Evaporador indus- } \\
\text { trial de plafón }\end{array}$ & 4 unidades & $\begin{array}{l}\text { Evaporador para cámaras frigoríficas marca Stefani con } \\
4 \text { salidas. }\end{array}$ \\
$\begin{array}{l}\text { Candil reflector } \\
\text { industrial }\end{array}$ & 6 unidades & Reflector industrial de campana 14" de 85 watts. \\
\hline
\end{tabular}

Elaboración propia

\subsubsection{Procedimiento}

Mediante la herramienta de mapeo de la cadena de valor o value stream mapping (VSM) de los procesos que se llevan a cabo, se muestra el suministro de los productos del almacén.

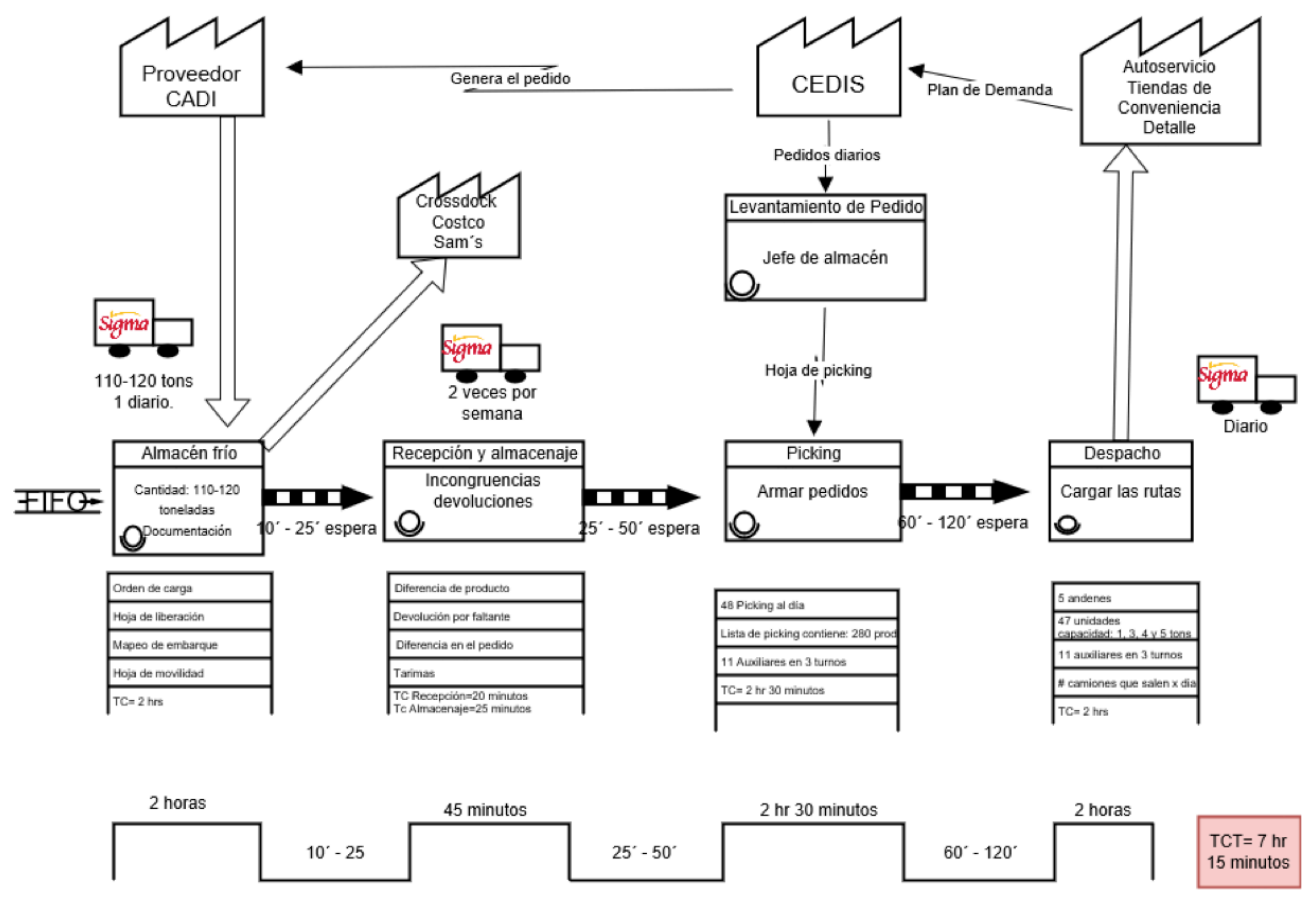

Figura 11. Esquema de la cadena de valor (VSM)

Elaboración propia

El CEDIS de Cancún tiene como proveedor principal al centro de acopio de distribución (CADI) de Tepotzotlán, México, cuya planta de producción elabora y almacena los alimentos refrigerados y los envía diariamente a las zonas centro y sur del país. Este estudio se centralizó en el proceso de suministro del CADI hacia el CEDIS de Cancún, 
para la recepción, almacenamiento y despacho de sus productos. Particularmente, el proceso involucra la descarga y el acomodo de los productos en el almacén frío, debido a que este implica, según los investigadores, un factor de complejidad para el área del almacén de la empresa.

Mediante el VSM se detectó que en donde se desarrolla, principalmente, el proyecto es en el proceso de almacén frío. A continuación, se detallan las actividades implicadas en dicho proceso. Sin embargo, es importante mencionar todos los procesos involucrados.

- Almacén frío. El almacén frío es el espacio físico determinado por el CEDIS para el resguardo de la mercancía que surte diariamente el CADI. Cada día ingresan al almacén frío 115 toneladas, en promedio.

- Recepción. Esta actividad inicia a las 10:30 p. m., cuando el tráiler con producto enviado del CADI llega al andén correspondiente del almacén frío.

- Almacenaje y distribución. Una vez recibido el pedido, se dedican 2 horas diarias al acomodo del producto de acuerdo con la orden del día y tomando en cuenta la distribución y clasificación ABC del almacén.

- Picking. Esta actividad inicia con el pedido que genera el jefe de almacén en el sistema. La cantidad de surtido se determina por la cantidad de producto disponible.

- Despacho. Empieza cuando el jefe de almacén valida la cantidad de pedido y surtido que se generó en el picking. El pedido lo realiza el jefe de almacén en el sistema, dependiendo de las tiendas de autoservicio. Una vez realizado esto, las unidades de transporte son cargadas por los auxiliares del almacén en los 5 andenes que tiene el almacén frío.

\subsubsection{Propuesta para el procedimiento y la distribución}

El procedimiento general del almacén permanecería intacto y no se modificaría la distribución actual ni al procedimiento, debido a que únicamente se realizarían remodelaciones a 91 metros cuadrados del almacén, los cuales corresponden al área de producto resguardado, la oficina del jefe de almacén y un área externa al almacén la cual se utiliza en ocasiones para resguardar tarimas en malas condiciones.

\subsubsection{Análisis de información}

Para la propuesta, el producto sería trasladado dentro del almacén, principalmente, en tarimas de aproximadamente 750 kilogramos. Cada tarima cuenta con un promedio de 18 canastillas, las cuales contienen unidades sueltas de un solo producto de las diferentes familias. 
Con la propuesta, el área anexada aumentaría la altura del almacén a 13 metros, aproximadamente, por lo que las tarimas de esa área deberían ser trasladadas con el uso de un montacargas, cumpliendo todas las medidas de seguridad planteadas en la NOM-006-STPS-2014.

\subsection{Fase 3: estudio económico-financiero}

De acuerdo con la información obtenida, el almacén frío del CEDIS podría continuar operaciones por 5 años, inclusive 9 años, para poder, así, satisfacer la demanda potencial insatisfecha en su totalidad.

Con los resultados referentes a la capacidad futura, derivada del estudio técnico, se decidió evaluar la propuesta de inversión planteada.

\subsubsection{Costos de consumo de energía eléctrica}

Para la determinación de los costos por consumo eléctrico, corresponde a los equipos de enfriamiento que se adquirirían, así como se determinó en el estudio técnico. Para el cálculo se tomó en cuenta la cantidad y el consumo por equipo, en kilovatios hora (kWh), así como el tiempo de uso promedio por equipo. Este tiempo de uso se refiere a las horas en las que el equipo alcanza la mayor cantidad de energía para su funcionamiento en el almacén. En la tabla 4 se muestra el costo (en pesos mexicanos, MXN) por consumo eléctrico correspondiente.

Tabla 4

Tabla de consumo de energía eléctrica

\begin{tabular}{|c|c|c|c|c|c|c|}
\hline \multirow[b]{2}{*}{$\begin{array}{c}\text { Nombre } \\
\text { del equipo }\end{array}$} & \multicolumn{6}{|c|}{ Consumo de energía eléctrica } \\
\hline & Cantidad & $\begin{array}{c}\text { Consumo } \\
\text { en kilovatios }\end{array}$ & $\begin{array}{l}\text { Horas de } \\
\text { uso al día }\end{array}$ & $\begin{array}{l}\text { Consumo } \\
\text { kWh/día }\end{array}$ & $\begin{array}{c}\text { Costo en MXN } \\
\text { kWh /día }\end{array}$ & $\begin{array}{c}\text { Costo total } \\
\text { en MXN } \\
\text { por día }\end{array}$ \\
\hline $\begin{array}{l}\text { Compresor } \\
\text { de tornillo }\end{array}$ & 1 & 37 & 16 & 592 & 846,56 & 846,56 \\
\hline Evaporador & 4 & 3,6 & 24 & 86,4 & 123,55 & 494,21 \\
\hline Condensador & 1 & 8 & 12 & 96 & 137,28 & 137,28 \\
\hline \multirow{4}{*}{$\begin{array}{l}\text { Candil reflector } \\
\text { industrial }\end{array}$} & 6 & 0,85 & 24 & 20,4 & 29,17 & 175,03 \\
\hline & & & & & Total & 1653,08 \\
\hline & & & & & Total mensual & 49592,40 \\
\hline & & & & & Total anual & 603374,20 \\
\hline
\end{tabular}

Elaboración propia 


\subsubsection{Costos de mano de obra directa}

Para determinar los costos de mano de obra directa se estimó el número de auxiliares adicionales que serían necesarios de acuerdo con el incremento de la capacidad que existe en la situación actual y con la capacidad futura pronosticada.

Una vez obtenido lo anterior, se determinó el costo de mano de obra considerando a los 3 auxiliares. En la tabla 5 se muestra el cálculo del costo de mano de obra directa.

Tabla 5

Tabla de costo de mano de obra directa (en pesos mexicanos, MXN)

\begin{tabular}{|c|c|c|c|c|c|}
\hline \multicolumn{6}{|c|}{ Costo de mano de obra directa } \\
\hline Plaza & Cantidad & Turnos por día & Sueldo mensual & Sueldo anual & Sueldo total anua \\
\hline Auxiliares & 3 & 3 & 11000,00 & 132000,00 & 396000,00 \\
\hline Subtotal & & & & & 396000,00 \\
\hline Prestaciones & & & $35 \%$ & & \\
\hline Total & & & & & 534600,00 \\
\hline
\end{tabular}

Elaboración propia

\subsubsection{Costos de obra civil}

De acuerdo con la segunda alternativa propuesta, el terreno adicional que se pretende tendría dimensiones de 14,2 m ×9,42 m, según estudio técnico. Para ello, será necesario hacer unas adecuaciones en el terreno previas a la instalación de los paneles aislantes Isopol. En la tabla 6 se muestra el costo de la obra civil para adecuar el terreno adicional.

Tabla 6

Tabla de costo de obra civil (en pesos mexicanos, MXN)

\begin{tabular}{|c|c|c|c|c|}
\hline \multicolumn{5}{|c|}{ Costo de obra civil } \\
\hline Cantidad & $\begin{array}{l}\text { Unidad de } \\
\text { medida }\end{array}$ & Concepto & Precio unitario & Precio total \\
\hline 1 & & $\begin{array}{l}\text { Limpieza de terreno } \\
\text { adicional }\end{array}$ & 10000,00 & 10000,00 \\
\hline 4 & $14 \mathrm{~m}^{3}$ & Desalojo de escombro & 4000,00 & 16000,00 \\
\hline 12 & Horas & Retroexcavadora & 800,00 & 9600,00 \\
\hline 1 & $14 \mathrm{~m}^{3}$ & Cargado a mano & 4400,00 & 4400,00 \\
\hline 656 & $m^{2}$ & $\begin{array}{l}\text { Levantamiento de nivel } \\
\text { del piso }\end{array}$ & 120,00 & 78720,00 \\
\hline
\end{tabular}


(continuación)

\begin{tabular}{cclcr}
\hline 5 & $14 \mathrm{~m}^{3}$ & Relleno & 2000,00 & 10000,00 \\
42,6 & $\mathrm{~m}^{3}$ & Cimentación & 1926,00 & 82047,60 \\
42,6 & $\mathrm{~m}^{2}$ & Preparación del suelo & 120,00 & 5112,00 \\
42,6 & $\mathrm{~m}^{3}$ & Aditivo & 365,00 & 15549,00 \\
\cline { 3 - 4 } & & & Subtotal & 231428,60 \\
& & IVA 16\% & 37028,58 \\
\cline { 3 - 4 } & & & Total & 268457,18 \\
\hline
\end{tabular}

Elaboración propia

\subsubsection{Determinación de la depreciación}

Para este proyecto se atribuyen los cargos de depreciación a los costos totales de producción. La determinación de costos totales de depreciación (en pesos mexicanos, MXN) aparece en la tabla 7.

Tabla 7

Tabla de depreciación (enpesos mexicanos, MXN)

\begin{tabular}{|c|c|c|c|c|c|c|c|}
\hline \multicolumn{8}{|c|}{ Depreciación } \\
\hline Concepto & $\begin{array}{c}\text { Valor } \\
\text { unitario }\end{array}$ & $\%$ & Año 1 & Año 2 & Año 3 & Año 4 & Año 5 \\
\hline Montacargas & 85000,00 & 0,25 & 21250,00 & $21.250,00$ & 21250,00 & 21250,00 & 21250,00 \\
\hline Obra civil & 268457,18 & 0,05 & 13422,86 & 13422,86 & 13422,86 & 13422,86 & 13422,86 \\
\hline $\begin{array}{l}\text { Equipo de } \\
\text { enfriamiento } \\
\text { e instalación } \\
\text { eléctrica }\end{array}$ & 1928455,89 & 35,0 & 674959,56 & 674959,56 & 674959,56 & 674959,56 & 674959,56 \\
\hline Total & & & 709632,42 & 709632,42 & 709632,42 & 709632,42 & 709632,42 \\
\hline
\end{tabular}

Elaboración propia

\subsubsection{Costos totales de producción}

Con la obtención de todos los costos anteriores se calcula el costo total de producción como se muestra en la tabla 8. 
Tabla 8

Tabla de costos totales de producción (en pesos mexicanos, MXN)

\begin{tabular}{lc}
\hline \multicolumn{2}{c}{ Costos totales de producción } \\
\hline \multicolumn{1}{c}{ Concepto } & \multicolumn{1}{c}{ Costo total } \\
\hline Costo de equipo de refrigeración & 68164,00 \\
Costo de mano de obra directa & 534600,00 \\
Costo de obra civil & 268457,18 \\
Depreciación & 709632,44 \\
\hline Total & 1542253,59 \\
\hline
\end{tabular}

Elaboración propia

\subsubsection{Costos de venta}

Para poder satisfacer los 3 diferentes canales de distribución, el CEDIS cuenta con 47 unidades vehiculares con capacidad desde 1 tonelada y media hasta 5 toneladas, de marca ISUZU. Repartiéndose las camionetas de la siguiente forma: 10 para autoservicio, 12 para conveniencia y 25 para venta por detalle.

Para la determinación de los costos de venta se consideran los conceptos de mantenimiento a la flotilla anual y el consumo de combustible (tabla 9).

Tabla 9

Gastos de venta y comercialización (en pesos mexicanos, MXN)

\begin{tabular}{lc}
\hline \multicolumn{2}{c}{ Gastos de venta } \\
\hline \multicolumn{2}{c}{ Comercialización } \\
\hline Concepto & Costo anual \\
\hline Mantenimiento anual & 33634,94 \\
Combustible & 227664,00 \\
\hline Total & 261298,94 \\
\hline
\end{tabular}

Elaboración propia

\subsubsection{Costos totales de operación}

De acuerdo con lo obtenido en la determinación de costos, se obtiene el costo total de operación del almacén frío del CEDIS, así como se muestra en la tabla 10. 
Tabla 10

Tabla de costos totales de operación (en pesos mexicanos, MXN)

\begin{tabular}{|c|c|}
\hline \multicolumn{2}{|c|}{ Costos totales de operación } \\
\hline Concepto & Costo total anual \\
\hline Consumo de energía eléctrica & 603374,20 \\
\hline Costo de equipo de refrigeración & 168164,00 \\
\hline Costo de mano de obra directa & 534600,00 \\
\hline Costo de obra civil & 268457,18 \\
\hline Costo de venta & 261298,94 \\
\hline Depreciación & 709632,42 \\
\hline Total & 2545526,73 \\
\hline
\end{tabular}

Elaboración propia

\subsubsection{Determinación de las inversiones}

Se determinan los activos fijos y diferidos para obtener el monto de la inversión total de la propuesta, para este punto no se incluye el capital de trabajo, ya que no se tomó en consideración para el monto total de la inversión.

El monto de la inversión total requerida se muestra en la tabla 11.

\section{Tabla 11}

Tabla de la inversión total de activos fijos y diferidos (en pesos mexicanos, MXN)

\begin{tabular}{|c|c|}
\hline \multicolumn{2}{|c|}{ Inversión total en activos fijos y diferidos } \\
\hline Concepto & Costo total \\
\hline Activos fijos de producción & 3610774,95 \\
\hline Activos diferidos de producción & 309345,87 \\
\hline Subtotal & 3920120,82 \\
\hline Imprevistos $5 \%$ & 196006,04 \\
\hline Total & 4116126,86 \\
\hline
\end{tabular}

Elaboración propia

\subsubsection{Determinación de la TMAR (tasa mínima aceptable de rendimiento)}

Para la determinación de la TMAR, se sugiere considerar la estabilidad de las ventas; anteriormente, se ha demostrado que los registros de las ventas proyectadas han ido incrementando año con año, mostrando tendencia en su comportamiento, lo cual no representa un riesgo para las ventas. Así como lo siguiere Baca Urbina (2013), en la 
metodología para el desarrollo del estudio económico financiero, se considera un $15 \%$ anual equivalente a la TMAR sin inflación.

\subsubsection{Determinación del costo de inventario}

Para la determinación del costo de inventario se considera el precio de venta por kilo, el cual se estimó en 62,05 MXN, en promedio a cada kilo vendido obtienen una ganancia del $45 \%$. Esto quiere decir que la diferencia entre el precio de venta por kilo y la ganancia se obtiene el costo por kilo, es decir, 34,13 MXN. En la tabla 12 se muestra el costo de inventario por kilo para el almacén frío.

Tabla 12

Tabla de costo de inventario por kilo (en pesos mexicanos, MXN)

\begin{tabular}{lc}
\hline \multicolumn{2}{c}{ Costo de inventario por kilo } \\
\hline Precio de venta & 62,05 \\
Porcentaje de ganancia & 45 \\
Ganancia & 27,92 \\
Precio costo & 34,13 \\
Capacidad en kilos & 115000,00 \\
\hline Total & 3924950,00 \\
\hline
\end{tabular}

Elaboración propia

\subsubsection{Determinación del punto de equilibrio}

Con base en la determinación de los costos totales de producción, los ingresos y los costos totales, se podrá calcular el punto en donde se igualan los ingresos con los costos variables y fijos.

Esto se obtiene mediante la siguiente fórmula:

$$
Q=\frac{C F}{(P-V)}
$$

donde:

$Q$ : punto de equilibrio

$C F:$ costos fijos

$P$ : precio de venta por kilogramo

$V$ : costo variable unitario (costo por kilogramo) 
Sustituyendo la fórmula, se determina la cantidad de equilibrio:

$$
Q=\frac{1969680,56}{(62,05-34,13)}=70547,30
$$

Esto quiere decir que se deberán vender 70547,30 kilos para poder llegar al punto de equilibrio.

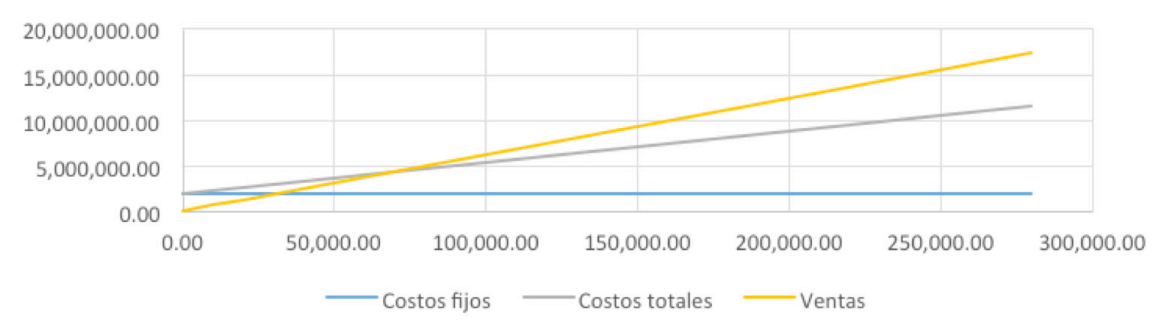

Figura 12. Punto de equilibrio

Elaboración propia

Con base en el punto de equilibrio encontrado, se determina que el tiempo que tomará llegar a este punto será de 9,5 meses.

\subsubsection{Determinación de los ingresos por ventas sin inflación}

El incremento de la demanda de productos incrementa cada año, con base en el registro de ventas pasadas se determinaron las ventas estimadas en kilos para los próximos 5 años. De igual forma, se estimó el precio de venta 62,05 MXN por kilo.

A partir de la información obtenida, se calcularon los ingresos que se tendrían de acuerdo con las ventas estimadas y el precio por kilo. El cálculo de los ingresos sin inflación se muestra en la tabla 13.

Tabla 13

Tabla de ingresos sin inflación (en pesos mexicanos, MXN)

\begin{tabular}{cccc}
\hline \multicolumn{4}{c}{ Ingresos sin inflación } \\
\hline Año & Ventas estimadas en kilos & Precio por kilo & Ingreso total \\
\hline 1 & 1065281,00 & 62,05 & 66100686,05 \\
2 & 1111301,00 & 62,05 & 68956227,05 \\
3 & 1157321,00 & 62,05 & 71811768,05 \\
4 & 1203341,00 & 62,05 & 74667309,05 \\
5 & 1249361,00 & 62,05 & 77522850,05 \\
\hline
\end{tabular}

Elaboración propia 


\subsubsection{Determinación del estado de resultados proforma}

Para el desarrollo de los estados de resultados, se presentarán 2 diferentes escenarios, los cuales se describen detalladamente.

La obtención de estos estados de resultados, permitirán la toma de decisiones que competen principalmente al almacén frío y al CEDIS de Sigma Alimentos Cancún.

\subsubsection{Estado de resultados sin inflación, sin financiamiento y con producción constante}

Para la construcción de este primer escenario, se toman las cifras de la inversión inicial del proyecto calculada anteriormente, corresponde al momento antes de realizar la inversión. No se considera la inflación y los flujos netos de efectivo permanecerán iguales cada año desde el año 1 al 5.

Tabla 14

Tabla de estados de resultados sin inflación, sin financiamiento y con producción constante (en pesos mexicanos, MXN)

\begin{tabular}{ccc}
\hline & Estado de resultados sin inflación, sin financiamiento y con producción constante \\
\hline+ & Ingresos & 5513922,22 \\
- & Costo de producción & 1542253,59 \\
- & Costo de ventas & 261298,94 \\
$=$ & Utilidades antes de impuestos & 3710369,69 \\
- & Impuestos 35\% & 1298629,39 \\
$=$ & Utilidad después de impuestos & 2411740,30 \\
+ & Depreciación & 709632,42 \\
$=$ & Flujo neto de efectivo & 3121372,72 \\
\hline
\end{tabular}

Elaboración propia

3.3.13.2 Estado de resultados con inflación, sin financiamiento y con producción constante Para este segundo escenario, se construye con las cifras obtenidas de los ingresos y los costos, solo que ahora se verán afectadas por la inflación. La tasa de inflación del año 2020 al 2024 incrementará en promedio un 3 \%, aproximadamente, según la página web Statista (3 de mayo del 2020). 
Tabla 15

Tabla de estado de resultados con inflación, sin financiamiento y con producción constante (en pesos mexicanos, MXN)

\begin{tabular}{|c|c|c|c|c|c|c|c|}
\hline \multicolumn{8}{|c|}{ Estado de resultados con inflación, sin financiamiento y con producción constante } \\
\hline & Año & 0 & 1 & 2 & 3 & 4 & 5 \\
\hline+ & Ingresos & 5513922,22 & 5679339,89 & 5849720,08 & 6025211,69 & 6205968,04 & 6392147,08 \\
\hline- & $\begin{array}{l}\text { Costo de } \\
\text { producción }\end{array}$ & 1542253,59 & 1588521,20 & 1636176,84 & 1685262,14 & 1735820,01 & 1787894,61 \\
\hline & $\begin{array}{l}\text { Costo de } \\
\text { ventas }\end{array}$ & 261298,94 & 269137,91 & 277212,04 & 285528,41 & 294094,26 & 302917,09 \\
\hline$=$ & $\begin{array}{l}\text { Utilidades } \\
\text { antes de } \\
\text { impuestos }\end{array}$ & 3710369,69 & 3821680,78 & 3936331,20 & 4054421,14 & 4176053,77 & 4301335,38 \\
\hline - & $\begin{array}{l}\text { Impuestos } \\
35 \%\end{array}$ & 1298629,39 & 1337588,27 & 1377715,92 & 1419047,40 & 1461618,82 & 1505467,38 \\
\hline$=$ & $\begin{array}{l}\text { Utilidad } \\
\text { después de } \\
\text { impuestos }\end{array}$ & 2411740,30 & 2484092,51 & 2558615,28 & 2635373,74 & 2714434,95 & 2795868,00 \\
\hline & Depreciación & 709632,42 & 730921,39 & 752849,03 & 775434,50 & 798697,54 & 822658,47 \\
\hline & $\begin{array}{l}\text { Flujo neto de } \\
\text { efectivo }\end{array}$ & 3121372,72 & 3215013,90 & 3311464,31 & 3410808,24 & 513132,49 & 3618526,47 \\
\hline
\end{tabular}

Elaboración propia

3.3.13.3 Estado de resultados sin inflación, sin financiamiento y con producción constante Considera la inversión inicial y el flujo neto de efectivo obtenido del año 1 al 5 . Adicional a esto, se calcula el valor de salvamento de la depreciación de activos en pesos mexicanos (MXN).

Con la misma TMAR del $15 \%$ se calcula el VPN. 
Tabla 16

Cálculo del VPN y TIR del escenario 1

\begin{tabular}{|c|c|c|}
\hline Años & $\begin{array}{c}\text { Flujo neto de efectivo } \\
\text { (en pesos mexicanos, MXN) }\end{array}$ & \\
\hline 0 & $-4116126,86$ & \\
\hline 1 & 3121372,72 & $\begin{array}{l}\text { Valor salvamento (en pesos } \\
\text { mexicanos, MXN) }\end{array}$ \\
\hline 2 & 3121372,72 & 26061,30 \\
\hline 3 & 3121372,72 & \\
\hline 4 & 3121372,72 & \\
\hline 5 & 3121372,72 & \\
\hline
\end{tabular}

Porcentaje TMAR

15

\begin{tabular}{cc}
\hline VAN en pesos mexicanos & 6360155,67 \\
\hline Porcentaje TIR & 70,62 \\
\hline
\end{tabular}

Elaboración propia

Con una TMAR del $15 \%$, el cálculo del VPN es 6360 155,67 MXN. Dado que el VPN calculado es un valor positivo y mayor a cero, el proyecto es convincente.

Con la obtención del VPN, podemos decir que la empresa, además de obtener el costo de los egresos y de recuperar los gastos, gana 6360 155,67 MXN de rentabilidad, eso significa el VPN. En caso de que fuera negativo, significa que la empresa no logra recuperar la inversión, por lo tanto, no se recomendaría la realización de la propuesta.

Con la TIR se quiere lograr que el VPN se iguale a cero, y eso se va a determinar con la obtención del porcentaje de la tasa interna de retorno, así se comprueba que se ha realizado correctamente. Significa que la TIR es del 70,02 \%, la que hace que el VPN sea cero.

Hasta este punto, de acuerdo con esos parámetros, se puede concluir que el proyecto es viable y conveniente económicamente para la empresa. Para comprobar lo anterior, se realiza el cálculo del VPN y TIR del segundo escenario. 
3.3.13.4 Estado de resultado con inflación, sin financiamiento y con producción constante Para este escenario, en caso de que se realizara el proyecto, se toma la inversión inicial determinada, así como también los flujos netos de efectivo, con el incremento en la tasa de inflación que tuvieron del año 1 al 5 significativamente.

De igual forma, el valor de salvamento para este escenario, sufre los efectos de la inflación.

Valor salvamento (en pesos mexicanos, MXN)

30212,19

Finalmente, la TMAR, para este escenario, sufre un incremento debido a la inflación. Se calcula una TMAR del $18 \%$.

El cálculo del VPN con la TIR se puede ver en la tabla 17.

Tabla 17

Tabla de cálculo del VPN y TIR del escenario 2

\begin{tabular}{cc}
\hline Años & $\begin{array}{c}\text { Flujo neto de efectivo } \\
\text { (en pesos mexicanos, MXN) }\end{array}$ \\
\hline 0 & $-4116126,86$ \\
1 & 3215013,90 \\
2 & 3311464,31 \\
3 & 3410808,24 \\
4 & 3513132,49 \\
5 & 3648738,66 \\
\hline Porcentaje TMAR & 18 \\
\hline VAN en pesos mexicanos & 6360155,67 \\
\hline Porcentaje TIR & 75,74 \\
\hline
\end{tabular}

Elaboración propia

En el primer escenario, con una TMAR del $15 \%$, el proyecto arrojó una TIR del 70,02\%, es decir, se obtuvo una ganancia por arriba de la TMAR del 55,02 \% puntos porcentuales. 
En el segundo escenario, con una TMAR del $18 \%$, el proyecto arroja una TIR del 75,4\%, se obtiene así una ganancia por encima de la TMAR del 57,74 \% puntos porcentuales.

\subsubsection{Evaluación económica}

Una vez que se hayan determinado los flujos netos de efectivo del proyecto, se pueden calcular el VPN (valor presente neto) y la TIR (tasa interna de retorno). Posteriormente, se comparan los valores obtenidos y se podrá determinar la conveniencia del proyecto.

\section{CONCLUSIONES Y DIRECCIONES PARA FUTURAS INVESTIGACIONES}

Los resultados obtenidos en el presente proyecto comprueban que al utilizar la metodología de análisis de proyectos realizando los estudios técnico y económico-financiero se puede llegar a propuestas de mejora para el funcionamiento de un almacén.

Se concluye que:

- Al realizar la expansión e inversión se aumentaría la capacidad de almacenaje de la empresa y podría abastecer la demanda futura, en al menos 9 años más, en el entendido que las ventas de la empresa siguiesen la misma tendencia de crecimiento.

- Mejoraría la seguridad de las áreas de trabajo, puesto que no habría necesidad de sobrepasar las áreas delimitadas para el almacenamiento de los productos.

- La empresa podría ser capaz de seguir abasteciendo las zonas actuales y tendría la capacidad de incrementar su mercado.

- Por las razones expuestas, se concluye que el proyecto sería viable comercial, técnica y financieramente.

Después de la puesta en marcha de la presente propuesta sobre la ampliación del almacén de Sigma Alimentos Cancún, las investigaciones consecuentes que podrían agregar valor a la empresa serían las relacionadas al estudio en conjunto con el área comercial referentes a la expansión de las rutas de transporte, ampliación de la cartera de clientes, con el fin de aprovechar el área adicional desde el primer año.

Contreras y Quintero (2012) realizaron una propuesta de mejora para la gestión de varios almacenes de materia prima de una empresa del sector químico, en ese proyecto utilizaron la metodología de evaluación de proyectos en la cual obtuvieron como resultado una modificación para gestionar la forma de almacenamiento, pudiendo incrementar la capacidad del almacén. En caso contrario, Sigma Alimentos Cancún modificó la forma de almacenamiento previamente al desarrollo de esta investigación, aprovecharon áreas del almacén que sobrepasaban la capacidad de almacenamiento de los productos sin 
dejar el área adecuada para la circulación de los trabajadores, incurriendo así en riesgos para sus colaboradores.

Albán (2016) realizó un estudio de factibilidad para la ampliación y diversificación de un almacén que resguardaba productos de pañalera y diversos artículos para niños. La propuesta de ampliación implicaba el cierre total del almacén, por un período de 3 meses, además, después de dicho período, el almacén tenía que ir abriendo parcialmente ciertas áreas, con lo cual el estudio financiero estimó pérdida de venta de productos. En el caso de la ampliación propuesta de Sigma Alimentos Cancún no se tiene que hacer ningún cierre que afecte la operación del almacén.

\section{REFERENCIAS}

Albán, V. (2016). Estudio de factibilidad de ampliación y diversificación de productos de almacén Rosarito de Babahoyo (tesis de grado). Universidad Regional Autónoma de los Andes, Quevedo, Ecuador. Recuperada de http://dspace.uniandes.edu.ec/ bitstream/123456789/7482/1/TUBADM048-2016.pdf

Baca Urbina, G. (2013). Evaluacion de proyectos (7. ${ }^{\text {a ed.). } . ~ M e ́ x i c o ~ D . F .: ~ M c G r a w-H i l l . ~}$

Cabrera Calva, R. C. (2017). VSM: Mapeo del flujo de valor. Análisis del mapeo de la cadena de valor. Recuperado de https://orion2020.org/archivo/cadenadevalor/ VSM22.pdf

Contreras, F., y Quintero, M. (2012). Propuesta de mejora para la gestión de almacén de las bodegas de materia de una empresa del sector químico y calzado (tesis de grado). Universidad Católica Andrés Bello, Caracas, Venezuela. Recuperada de http:// biblioteca2.ucab.edu.ve/anexos/biblioteca

Cruz, G., y Cháux, S. (2014). Análisis de factibilidad para la creación de un almacén de abastecimiento para un gupo de franquicias del sector alimentos (tesis de grado). Instituto Colombiano de Estudios Superiores de Incolda, Bogotá, Colombia. Recuperada de http://repository.icesi.edu.co/biblioteca_digital/ bitstream/10906/78671/1/analisis_factibilidad_creacion_2014.pdf

Dematteis, M., y Croci, S. (2014). Estudio de optimización del almacén de insumos en la planta sur de Quilmes (tesis de grado). Instituto Tecnológico de Buenos Aires, Buenos Aires, Argentina. Recuperado de https://ri.itba.edu.ar/bitstream/handle $/ 123456789 / 193 /$ Tesis\%20Final\%2023\%20de\%20Abril.pdf?sequence=1\&is Allowed $=$

Ferrer, J. (2017). Proyecto de ampliación del almacenamiento de materias primas corrosivas en una empresa de fertilizantes ecológicos y evaluación de los riesgos del personal profesionalmente expuesto en dicho almacén (trabajo de investigación). 
Universidad de Valencia, Valencia, España. Recuperada de https://riunet.upv.es/ bitstream/handle/10251/106484/53944288L_TFG_15307910592654901979259 234866614. pdf?sequence=1\&isAllowed=y

INEGI. (s.f.). Quintana Roo. Recuperado de http://cuentame.inegi.org.mx/monografias/ informacion/qroo/

Locher, D. (2008). Value stream mapping for lean development: a how to guide for stramling time to market. New York: Taylor \& Francis Group.

Muñoz Negrón, D. F. (2009). Administración de operaciones. Enfoque de administración de procesos de negocios. México D.F.: Cengage Learning Editores.

Muther, R., y Haganas, K. (1970). Systematic handling analysis (2. ${ }^{\mathrm{a}}$ ed.). Management \& Industrial Research Publications.

Núñez, E. (1997). Contenido y alcance del estudio de factibilidad. En Guía para la preparacion de proyectos de servicios públicos municipales (pp. 37-45). Instituto Nacional de Administración Pública, A. C. Recuperado de https://archivos.juridicas.unam. $\mathrm{mx} / \mathrm{www} / \mathrm{bjv} / \mathrm{libros} / 3 / 1430 / 6 . \mathrm{pdf}$

Sigma Alimentos. (31 de diciembre del 2017). Reporte anual. Recuperado de https://www. sigma-alimentos.com/wp-content/uploads/2019/03/Annual-Report-2017.pdf

Sigma Alimentos. (13 de junio del 2019). This is Sigma. Recuperado de https://www. sigma-alimentos.com/our-company/

Statista. (3 de mayo del 2020). Tasa de inflación global de 2014 a 2024. Recuperado dehttps://es.statista.com/estadisticas/495587/tasa-de-inflacion-global-respectoal-ano-anterior/

Vivanco, J. (2017). Sigma adquiere empresa con operaciones en Rumania. Recuperado de https://www.sigma-alimentos.com/wp-content/uploads/2019/03/2017-Sigmaadquiere-empresa-con-opera Vivanco ciones-en-Rumania-.pdf

White, S. A., y Miers, D. (2009). Guía referencia y modelado BPMN. Comprendiendo y utilizando BPMN. Lighthouse Point, Florida: Future Strategies Inc. Recuperado de http://futstrat.com/books/book_images/Guia\%20de\%20Referencia\%20y\%20 Modelado\%20BPMN\%20chap1-2.pdf 
